\title{
Adição e subtração em Davýdov
}

\author{
Josélia Euzébio da Rosa \\ Professora, UNISUL - SC \\ joselia.rosa@unisul.br
}

\author{
Ademir Damazio \\ Professor, UNESC - SC \\ add@unesc.net
}

\section{Ester de Souza Bitencourt Alves}

Professora, Rede Pública - SC

esterr_alvess@hotmail.com

\begin{abstract}
Resumo
O presente artigo expressa a investigação do movimento conceitual apresentado por Davýdov e seus colaboradores ao proporem o ensino de adição e subtração. Os dados da pesquisa, de natureza teórica, são constituídos por seis tarefas extraídas dos livros didáticos e de orientação ao professor. Durante a análise, constatamos que as tarefas davydovianas são desenvolvidas, inicialmente, por meio de ações objetais. No processo, são introduzidos os esquemas abstratos e a reta numérica. Estas representações compõem o elemento mediador que possibilita elevar as ações objetais ao plano mental. Os conceitos de adição e subtração são introduzidos com base na relação todo-partes de grandezas discretas e contínuas, na interconexão entre as significações aritméticas, algébricas e geométricas.
\end{abstract}

Palavras-chave: Teoria Histórico-Cultural; Proposições davydovianas; Adição; Subtração.

\section{Addition and subtraction by Davýdov}

\begin{abstract}
In this work it was investigated the movement proposed by Davýdov and his co-workers when they have suggested to teach addition and subtraction. The data are theoretical and they are constituted by three tasks from textbooks and from professor guides. During the analysis it was observed that tasks in Davýdov style are developed firstly by object actions. During the process, the abstract schemes and the number line are introduced. These representations compose the mediator element which enable elevate the object actions to the mental plan. The concepts about addition and subtraction are introduced based on the part-whole relationship of discrete and continuous quantities, in the interconnection among arithmetic, algebraic and geometric significances.
\end{abstract}

Keywords: Historic-cultural theory; Propositions by Davýdov; Addition; Subtraction. 


\section{Introdução}

O presente artigo volta-se à análise das seis tarefas de ensino propostas por Davýdov e seus colaboradores para introdução do conceito de adição e subtração. Davýdov (Давыдов), seguidor de Vygotsky, elaborou uma proposta de ensino fundamentada na Teoria Histórico-Cultural que foi publicada em coautoria com seus colaboradores, tais como Gorbov (Горбов), Mikulina (Микулина) е Savieliev (Савельева), em forma de livros didáticos (ДАВЫДОВ et al, 2012) e livros de orientações metodológicas ao professor (ГОРБОВ, МИКУЛИНА е САВЕЛЬЕВА, 2009). Os dados da investigação foram extraídos dos referidos livros originalmente escritos em russo e traduzidos para a língua portuguesa por Elvira Kim.

Vasili Vasilievich Davýdov, de origem russa, nasceu em 1930 e morreu em 1998. Membro da Academia de Ciências Pedagógicas, doutor em Psicologia, foi professor universitário. Pertenceu à terceira geração de psicólogos soviéticos desde os trabalhos da equipe inicial de Vigotsky (LIBÂNEO, 2004).

$\mathrm{O}$ foco da proposta davydoviana consiste em

[...] formar nas crianças representações materialistas firmes para produzir nelas o pensamento independente e melhorar significativamente a formação artística e estética; elevar o nível ideológico e teórico do processo de ensino e educação, expor com precisão os principais conceitos e as ideias básicas das disciplinas escolares; erradicar quaisquer manifestações de formalismo no conteúdo e métodos de ensino e no trabalho de formação, e aplicar amplamente as formas e métodos ativos de ensino, etc. (DAVÍDOV, 1988, p. 170-171).

Para o referido autor, a educação escolar deve ter, como objetivo principal, o desenvolvimento do pensamento teórico dos estudantes por meio da apropriação dos conceitos científicos. Davýdov (1982) propõe que o ensino seja organizado de modo a propiciar a generalização teórica, e "opõe-se à estrutura da educação de sua época (e cultura) cuja ênfase se dava na busca mecânica de resultados matemáticos" (FERREIRA, 2005, p. 25). A premissa básica davydoviana (1982) é de que o melhor ensino é aquele que promove o desenvolvimento do pensamento teórico nos estudantes em nível contemporâneo, o que requer métodos e conteúdos de ensino adequados.

Tendo como referência esses pressupostos davydovianos, o objetivo da presente investigação é: analisar o movimento conceitual proposto por Davýdov e seus colaboradores ao proporem o ensino de adição e subtração. Para tanto, centra-se numa sequência de seis tarefas davydovianas, a seguir apresentas. 
Tarefa 1: Qual é o valor representado pela letra A, ao se considerar C como unidade de medida (Figura 1)? (ГОРБОВ, МИКУЛИНА е САВЕЛЬЕВА, 2009).

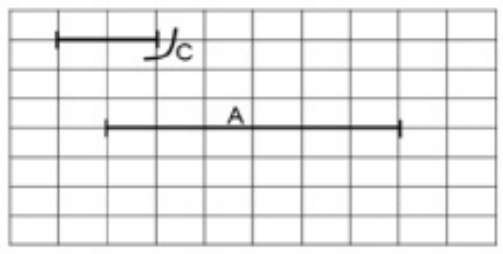

$A=\square c$

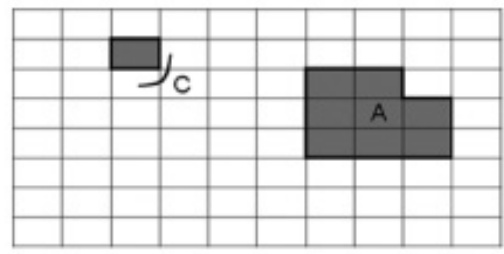

$A=\square c$

Figura 1 - Tarefa 1: Comparação entre grandezas

Fonte: Elaboração nossa com base na proposição davydoviana

Ao sobrepor o comprimento de medida $\mathrm{C}$ ao comprimento com medida $\mathrm{A}$, verifica-se que a unidade de medida de comprimento (C) repete-se três vezes. Logo: $\mathrm{C}+\mathrm{C}+\mathrm{C}=3 \mathrm{C}$. Deste modo, fica estabelecida a equivalência $\mathrm{A}=3 \mathrm{C}$ que, no contexto de conjuntos finitos, "se traduz pela igualdade" (CARAÇA, 1951, p. 9). $\mathrm{O}$ mesmo ocorre para determinar a quantidade de vezes que a unidade de medida de área $\mathrm{C}$ cabe na superfície com medida $\mathrm{A}$. Assim, $\mathrm{C}+\mathrm{C}+\mathrm{C}+\mathrm{C}+\mathrm{C}+\mathrm{C}+\mathrm{C}+$ $\mathrm{C}=8 \mathrm{C}$, de modo que a equivalência obtida consiste em: $\mathrm{A}=8 \mathrm{C}$ (Figura 2). Vale ressaltar que a operação da adição não só está inter-relacionada com a subtração, mas, também, com a multiplicação.

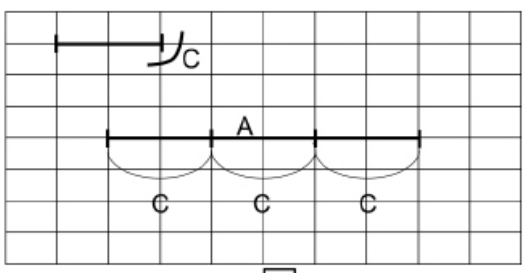

$A=3 \mathrm{C}$

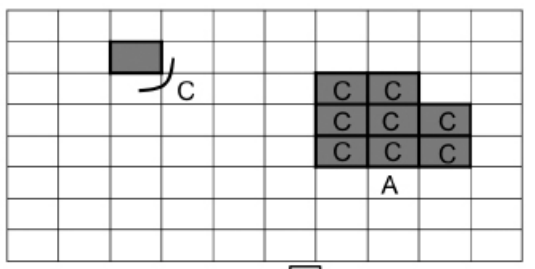

$A=8 \mathrm{C}$

Figura 2 - Tarefa 1: Relação entre as grandezas comprimento e área

Fonte: Elaboração nossa com base na proposição davydoviana

O valores aritméticos 3 e 8 determinados para a medida genérica $A$, consistem na medida da grandeza em relação à unidade de medida (CARAÇA, 1951). Para Costa (1866, p. 9, grifo do autor), "medir uma grandeza é determinar quantas vezes ela con- 
tém a grandeza da sua espécie, que serve de unidade de medida. Por consequência os números são expressões de medida das grandezas". O mesmo ocorre em Davýdov, ou seja, os números 3 e 8 expressam, respectivamente, a medida do comprimento e da área.

A proposição davydoviana para o ensino dos conceitos matemáticos é mediada pelas relações entre grandezas discretas e contínuas, tais como: comprimento com comprimento, área com área, volume com volume, e assim por diante (ROSA, 2012). Costa (1866, p. 9) define grandeza como "tudo quanto é suscetível de aumento ou diminuição; como a extensão, o tempo, o peso, o movimento, etc., etc.". Vale mencionar que outros conceitos matemáticos são considerados na proposição davydoviana, tais como equivalência e desigualdade.

A partir das relações entre grandezas é possível expressar a medida de uma delas ao se tomar outra da mesma espécie como unidade de medida. Esta "é todo e qualquer objeto que se toma para termo de comparação com todos os outros objetos da sua espécie" (COSTA, 1866, p. 9). Ainda para o mesmo autor, o número "é a reunião de muitas unidades de uma mesma espécie. E, também, a unidade é considerada como um número". Em função de tais fundamentos matemáticos, Davýdov (1982, p. 431) defende que o objetivo do ensino de Matemática, desde o primeiro escolar, "é criar nos alunos uma concepção circunstanciada e válida de número real a partir do conceito de grandeza".

As tarefas davydovianas propõem uma análise mediada pelos símbolos matemáticos. Revelar "e expressar em símbolos o ser mediatizado das coisas, sua generalidade, é efetuar a passagem para a produção teórica da realidade" (DAVÝDOV, 1982, p. 303). Esta é uma das razões pelas quais os símbolos matemáticos são contemplados nas tarefas de Davýdov e seus colaboradores, desde o primeiro ano do Ensino Fundamental. Os estudos de Davýdov (1982, p. 433-434) mostram que o "simbolismo literal, as correspondentes fórmulas literais e a interconexão das mesmas, são consolidativos das propriedades fundamentais das grandezas, são inteiramente acessíveis às crianças".

No que se refere ao objeto do presente estudo, Davýdov e seus colaboradores apresentam o conceito de adição interconectado com a subtração, a partir da análise da relação entre grandezas e na inter-relação das significações aritméticas, algébricas e geométricas.

De acordo com Aleksandrov (1976), a aritmética e a geometria não só se aplicam uma à outra, como também são fontes de outros métodos, ideias e teorias gerais. Para medir comprimentos, por exemplo, adota-se certa unidade e se calcula quantas vezes é possível repetir esta operação: o primeiro passo (aplicação) é de caráter geométrico, o segundo (cálculo) é aritmético, e a relação entre comprimento em medição e unidade de medida é de caráter algébrico (ROSA, 2012). 
Tarefa 2: O professor solicita às crianças que observem as duas situações dadas (Figura 3) e apresenta as seguintes questões: quais grandezas foram consideradas nas duas relações? O que foi utilizado para medir as duas grandezas? Em seguida, sugere-se que as crianças determinem as medidas desconhecidas com o apoio da reta numérica (ГОРБОВ, МИКУЛИНА е САВЕЛЬЕВА, 2009).
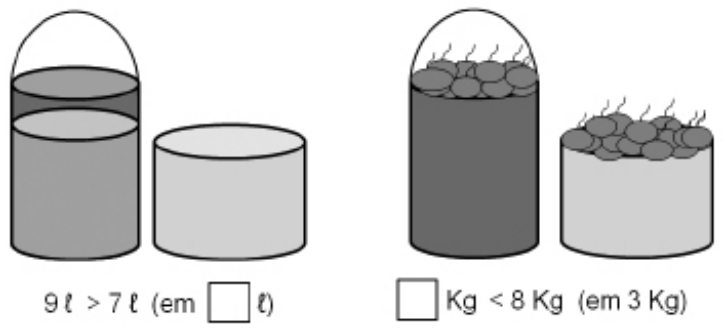

Figura 3 - Tarefa 2: Relação de desigualdade entre grandezas

Fonte: Elaboração nossa com base na proposição davydoviana

Para desenvolver a tarefa, o professor orienta para que as crianças respondam às perguntas na ordem em que foram anteriormente apresentadas, com base nas situações ilustradas (Figura 3). Ao analisar a primeira relação, verifica-se que nos recipientes com líquidos, a grandeza em questão é o volume e a unidade de medida utilizada foi o litro.

Para determinar a diferença 9 e 7, as crianças realizarão a operação de subtração por meio da reta numérica (Figura 4).

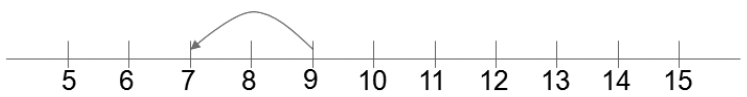

Figura 4 - Tarefa 2: Identificação da diferença na reta numérica

Fonte: Elaboração nossa com base na proposição davydoviana

O registro na reta numérica requer a compreensão da relação todo-partes. Esta já foi introduzida no material didático referente ao primeiro ano do Ensino Fundamental da proposição davydoviana (ROSA, 2012). Assim, 9 litros correspondem ao valor do todo e 7 litros correspondem a uma das partes que compõem o todo. A outra parte desconhecida refere-se à diferença (2 litros). 
Na segunda relação entre grandezas, apresentada na figura 3, há frutas nos recipientes. Logo abaixo deles consta a informação sobre a unidade de medida (Kg), que permite inferir sobre a grandeza considerada: a massa. Com o apoio da reta numérica (Figura 5), o valor desconhecido (5 unidades) é determinado.

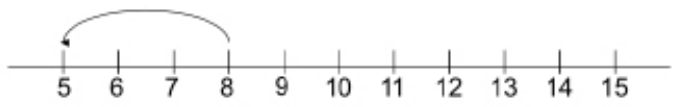

Figura 5 - Tarefa 2: Operação da subtração 8 - 3

Fonte: Elaboração nossa com base na proposição davydoviana

O todo é constituído por 8 quilogramas, e 3 quilogramas correspondem a uma das partes que compõem o todo. Portanto, para determinar o valor da outra parte, a operação realizada também foi uma subtração.

Com base na análise das tarefas 1 e 2, verificamos que Davýdov e seus colaboradores não seguem um movimento linear no procedimento de resolução. Na tarefa 1, por exemplo, as igualdades foram determinadas sem o apoio da reta numérica. $\mathrm{Na}$ tarefa 2, por sua vez, a orientação é para o retorno da utilização de tal representação geométrica, já iniciada no material referente ao primeiro ano do Ensino Fundamental. Ou seja, o processo de elevação das operações do plano real (relação entre grandezas) ao plano mental é marcado por avanços e retrocessos mediados pela reta numérica.

Ao analisar a tarefa 2 com base em Caraça (1951), concluímos, no primeiro momento, que $9-7=\underline{2}$. O número 9 é o minuendo, 7 o subtraendo e o número 2 , o resto ou a diferença. No segundo momento, embora a operação realizada também tenha sido uma subtração $(8-3=\underline{5})$, o valor desconhecido não era o resto ou a diferença (3), mas o subtraendo (5). Este, no contexto da operação realizada, assume o papel de resto, ainda que na situação em análise seja o subtraendo. Deste modo, foram determinados, por meio da subtração, os valores correspondentes à diferença e ao subtraendo, respectivamente.

Tarefa 3: A tarefa consiste em desenvolver as seguintes operações (ГОРБОВ, МИКУЛИНА е САВЕЛЬЕВА, 2009):
$17 \ell-7 \ell$
$8 \mathrm{~m}+8 \mathrm{~cm}$
$6 \mathrm{t}+1 \mathrm{~m}$
$9 \mathrm{~g}-2 \mathrm{~g}$
$8 \mathrm{~kg}+2 \mathrm{~kg}$
$9 \mathrm{dm}-5 \mathrm{dm}$

O objetivo de Davýdov e seus colaboradores, na tarefa em análise (3), é que as crianças compreendam que as respostas precisam ter caráter geral. Ou seja, medimos a capacidade (e não a água ou os litros), a massa (e não as maçãs ou quilos), etc. (ГОРБОВ, МИКУЛИНА е САВЕЛЬЕВА, 2009). Os resultados a serem atingidos pelas crianças são apresentados, sublinhados, na sequência. 
$17 \ell-7 \ell=\underline{10 \ell} ; \quad 8 \mathrm{~kg}+2 \mathrm{~kg}=\underline{10 \mathrm{~kg}} ;$

$9 \mathrm{dm}-5 \mathrm{dm}=\underline{4 \mathrm{dm}} ; \quad 8 \mathrm{~m}+8 \mathrm{~cm}=\underline{8 \mathrm{~m} \mathrm{e} 8 \mathrm{~cm}} ;$

$6 \mathrm{t}+1 \mathrm{~m}=\underline{\text { não é possível, pois são grandezas distintas; }}$

$9 \mathrm{~g}-2 \mathrm{~g}=\underline{7 \mathrm{~g}}$.

Para desenvolver as operações corretamente, as crianças devem compreender as relações entre as grandezas. Não basta somente operar com os números. Além disso, são necessárias, também, outras reflexões durante seu desenvolvimento. Em outras palavras, para desenvolver as operações de adição e subtração é fundamental compreender o número como expressão da relação entre grandezas. A conclusão a ser obtida, a partir da tarefa 3 , é que somente torna-se possível somar ou subtrair grandezas da mesma espécie.

Tarefa 4: Qual das sentenças apresentadas (Figura 6) não é possível determinar com base no esquema? (ГОРБОВ, МИКУЛИНА е САВЕЛЬЕВА, 2009).

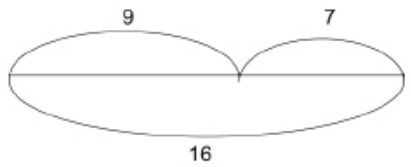

$\begin{array}{rcl}9+7 & 16+7 & 16-7 \\ 16-9 & 7+9 & 16-7-9\end{array}$

Figura 6 - Tarefa 4: Relação todo-partes

Fonte: Elaboração nossa com base na proposição davydoviana

Todas as sentenças (Figura 6) poderiam ser resolvidas, na tarefa em análise, se não fosse estabelecida uma condição para tal: resolvê-las a partir do esquema. A relação todo-partes, expressa no esquema, impossibilita a realização da operação 16 + 7. Trata-se de uma impossibilidade proposta por Davýdov e seus colaboradores para verificar a compreensão, ou não, pela criança, da referida relação.

Outra característica da proposta de Davýdov e seus colaboradores é que as operações de adição e subtração são apresentadas como inversas entre si. Tal inversão consiste no seguinte: "dado o resultado da operação e um dos dados, determinar o outro dado" (CARAÇA, 1951, p. 20, grifos do autor). A partir desta definição apresentada por Caraça, elaboramos a seguinte síntese de movimento inverso entre as operações de adição e subtração:

Adição $\rightarrow$ subtração: dada a soma e o adicionador, determinar o adicionando. Subtração $\rightarrow$ adição: dada a diferença e o subtraendo, determinar o minuendo. 
Com base na operação particular $9+7=16$, apresentada por Davýdov e seus colaboradores na tarefa em análise, temos (Figura 7):

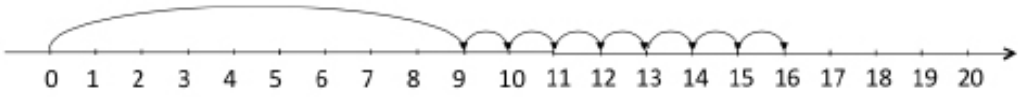

Figura 7 - Tarefa 4: Representação geométrica da operação de adição

Fonte: Elaboração nossa com base na proposição davydoviana

A reta e os arcos se constituem em mediadores para a expressão geral da adição, qual seja: $\mathbf{a}+\mathbf{b}=\mathbf{c}$. Ao número $\boldsymbol{a}$ dá-se o nome de adicionando, ao $\boldsymbol{b}$, adicionador. Na soma, o adicionando representa um papel passivo, e o adicionador um papel ativo (CARAÇA, 1951).

É nesse contexto que a subtração se constitui como a operação inversa da adição. Para tanto, retomemos a operação particular anteriormente apresentada: 9 $+7=16$. A representação geométrica da sua operação inversa (Figura 8), a partir da definição apresentada por Caraça (1951), consiste em: dada a soma (16) e o adicionador (7), determinar o adicionando (9). Então, $16-7=$

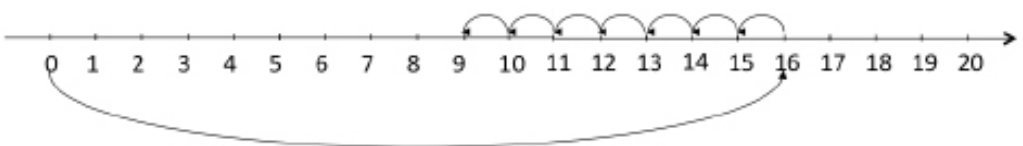

Figura 8 - Tarefa 4: Representação geométrica da operação de subtração

Fonte: Elaboração nossa com base na proposição davydoviana

De modo similar à adição, os procedimentos na reta permitem atingir a expressão geral da subtração: $\mathbf{c}-\mathbf{b}=\mathbf{a}$. Subtração é a operação pela qual se determina um número $\boldsymbol{a}$ que, somado com $\boldsymbol{b}$, resulta em $\boldsymbol{c}$. Portanto: $\mathbf{c}-\mathbf{b}=\mathbf{a} \rightarrow \mathbf{a}+\mathbf{b}=\mathbf{c}$ (CARAÇA, 1951).

A representação genérica da operação $a+b=c($ Figura 9) consiste em:

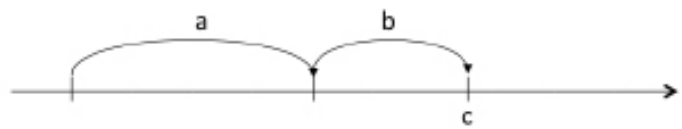

Figura 9 - Tarefa 4: Representação genérica da operação de adição Fonte: Elaboração nossa com base em Caraça 
O movimento inverso da operação aditiva, apresentado anteriormente (Figura 6), pode ser assim representado (Figura 10):

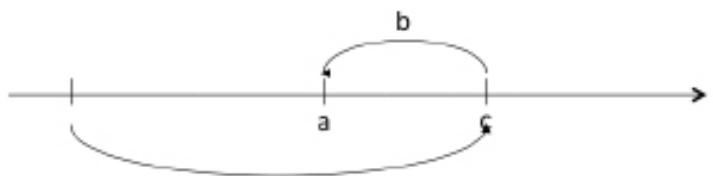

Figura 10 - Tarefa 4: Representação genérica da operação da subtração Fonte: Elaboração nossa com base em Caraça

Ou seja, $c-b=a$.

Nas representações genéricas apresentadas nas figuras anteriores (9 e 10) está objetivado o movimento interno entre a operação de adição e sua operação inversa, a subtração. O referido movimento é expressão das propriedades matemáticas apresentadas por Caraça (1951). Tal constatação permite afirmar que a proposição davydoviana contempla as significações científicas de tais operações, pois:

A inversão consiste em - dada a soma e uma das parcelas, determinar a outra. Deveria haver duas operações inversas, conforme se pedisse o adicionando ou o adicionador, mas, em virtude da propriedade comutativa da adição, os papéis das duas parcelas podem trocar-se, e as duas inversas fundem-se numa só, que se chama subtração (CARAÇA, 1951, p. 20, grifos do autor).

Em continuidade com a análise das demais propriedades das operações de adição e subtração envolvidas na tarefa em referência, temos:

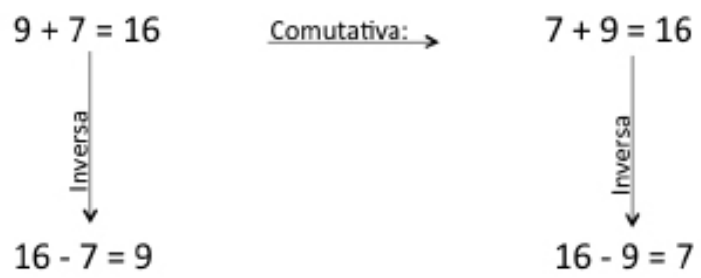

Figura 11 - Tarefa 4: Inter-relação entre as propriedades da adição e subtração Fonte: Elaboração nossa com base em Caraça 
A representação literal da operação comutativa, segundo Caraça (1951, p. 18), consiste em “ $a+b=b+a$ ". Portanto, na operação comutativa $7+9=16$, temos a seguinte representação geométrica (Figura 12):

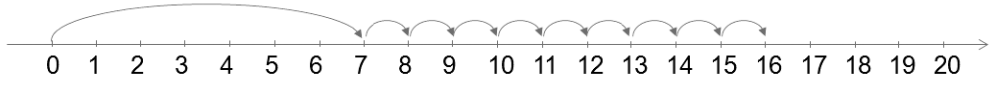

Figura 12 - Tarefa 4: Representação geométrica da operação comutativa Fonte: Elaboração nossa com base em Caraça

A operação inversa, resultante da comutatividade $(16-9=7)$, geometricamente, pode ser assim representada (Figura 13):

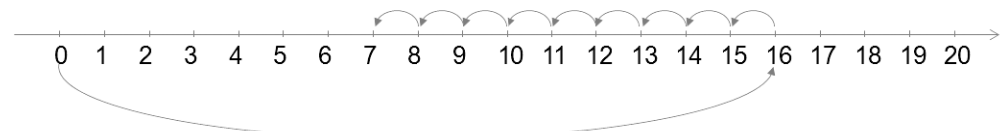

Figura 13 - Tarefa 4: Representação geométrica da operação inversa da comutativa Fonte: Elaboração nossa com base em Caraça

Deste modo, em Davýdov, a relação todo-partes constitui a base para a introdução das operações de adição e subtração no contexto das propriedades matemáticas em nível teórico.

Tarefa 5: Determine o comprimento (C) do fio, parte curva (Figura 14). Construa um esquema que represente a relação todo-partes (ГОРБОВ, МИКУЛИНА e САВЕЛЬЕВА, 2009).

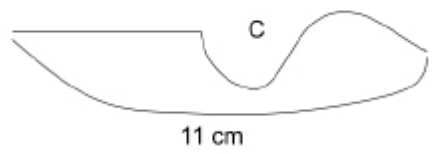

Figura 14 - Tarefa 5: Comprimento $\mathrm{C}$ do fio na parte curva

Fonte: Elaboração nossa com base na proposição davydoviana

Nessa tarefa (Figura 14), o valor do todo é conhecido (11 cm), mas os valores das partes são desconhecidos. Para determiná-las, faz-se necessário medir o segmento de reta com uma régua. Com a identificação do valor de tal medida, é possível calcular o comprimento da parte curva. A título de ilustração, supomos que o comprimento do segmento de reta seja 4 centímetros (Figura 15). 


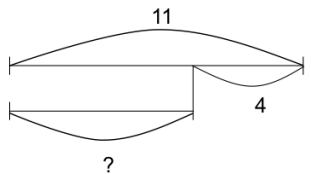

Figura 15 - Tarefa 5: Relação todo-partes

Fonte: Elaboração nossa com base na proposição davydoviana

No esquema anterior (Figura 15), o número 11 representa o valor do todo, e 4 uma das partes conhecidas (medida do segmento de reta). Para determinar a medida do comprimento da parte curva (desconhecida), basta subtrair a parte formada pelo segmento de reta $(4 \mathrm{~cm})$ do todo $(11 \mathrm{~cm})$. O movimento proposto na tarefa davydoviana para determinar o valor da medida do comprimento na parte curva é realizado a partir da operação de subtração. Logo, o valor da medida desconhecida é $7 \mathrm{~cm}$, pois $11-4=7$.

O comprimento é uma grandeza contínua. De acordo com Davýdov (1982), a operação apenas com as grandezas discretas não permite a revelação, no ensino, do campo dos números reais em seu nível teórico-abstrato, mas limita-se apenas aos naturais. Tal limitação conceitual não atende a necessidade de "mostrar francamente às crianças a essência abstrata das matemáticas, inculcar-lhes a faculdade de fazer abstrações e de aproveitar sua força teórica" (DAVÝDOV, 1982, p. 157). Por isso, para o autor em referência, é necessário contemplar, também, as operações com grandezas contínuas.

Davýdov (1982) e seus colaboradores propõem, às crianças, a medição de grandezas diversas e com diferentes unidades de medidas formadas por grandezas da mesma espécie desde o primeiro ano do Ensino Fundamental. O objetivo é propor tarefas com teor científico, correspondente ao estágio mais desenvolvido que a ciência atingiu na atualidade. Porém, alerta que é obrigação da educação escolar proporcionar aos estudantes as abstrações e generalizações em nível inteiramente moderno.

Tarefa 6: Com base na relação todo-partes representada no modelo (Figura 16), complete o quadro (ГОРБОВ, МИКУЛИНА е САВЕЛЬЕВА, 2009).

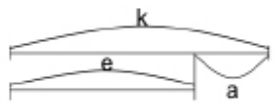

\begin{tabular}{|c|c|c|c|c|c|c|}
\hline$k$ & 8 & 10 & 9 & 10 & 14 & 8 \\
\hline e & 6 & 7 & 5 & 8 & 10 & 5 \\
\hline$a$ & 2 & 3 & 4 & 2 & 4 & 3 \\
\hline
\end{tabular}

Figura 16 - Tarefa 6: Esquema e quadro

Fonte: Elaboração nossa com base na proposição davydoviana 
A tarefa (Figura 16) será desenvolvida a partir de um modelo genérico expresso no esquema na relação todo-partes, o que é possível compor as seguintes operações:

(1) $\mathrm{e}+\mathrm{a}=\mathrm{k} \rightarrow$ operação da adição;

(2) $\mathrm{a}+\mathrm{e}=\mathrm{k} \rightarrow$ comutativa da adição (1);

(3) $\mathrm{k}-\mathrm{a}=\mathrm{e} \rightarrow$ inversa da adição (1), ou seja, a subtração;

(4) $\mathrm{k}-\mathrm{e}=\mathrm{a} \rightarrow$ inversa da comutativa da adição (2).

Deste modo, para o cálculo do valor $\boldsymbol{k}$, podemos operar com a adição (e + a) ou a sua comutativa $(\mathrm{a}+\mathrm{e})$. Para determinar o valor $\boldsymbol{e}$, utilizamos a operação inversa da adição, ou seja, a subtração $(\mathrm{k}-\mathrm{a})$. Assim, para calcular $\boldsymbol{a}$, aplicamos a operação inversa da comutativa $(\mathrm{k}-\mathrm{e})$. A resolução da tarefa culmina com o preenchimento do quadro:

\begin{tabular}{|c|c|c|c|c|c|c|}
\hline $\mathbf{k}$ & 8 & 10 & 9 & 10 & 14 & 8 \\
\hline $\mathbf{e}$ & 6 & 7 & 5 & 8 & 10 & 5 \\
\hline $\mathbf{a}$ & 2 & 3 & 4 & 2 & 4 & 3 \\
\hline
\end{tabular}

\section{Figura 17 - Tarefa 6: Quadro preenchido}

Fonte: Elaboração nossa com base na proposição davydoviana

As operações realizadas, em cada coluna do quadro, para determinar os valores desconhecidos, foram: na segunda e quinta colunas, a operação de adição ou a sua comutativa; na terceira e sexta colunas, a operação inversa da adição (subtração), e na primeira e quarta colunas, a operação inversa resultante da comutativa.

Na segunda coluna, por exemplo, foi realizado o seguinte movimento operacional (Figura 18):

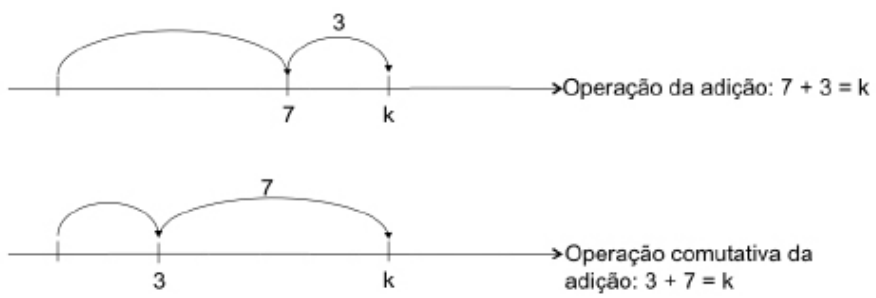

Figura 18 - Tarefa 6: Escolha da operação aritmética

Fonte: Elaboração nossa com base na proposição davydoviana 
Portanto, o resultado da operação $7+3$ é o mesmo que o resultado da operação $3+7$. Ambas, pela propriedade comutativa, resultam em $\boldsymbol{k}(\mathrm{k}=10)$.

$\mathrm{Na}$ terceira coluna, o valor desconhecido era $\boldsymbol{e}$, por isso, a operação considerada foi a inversa da adição: $\mathrm{k}-\mathrm{a}=\mathrm{e}$, conforme representação geométrica a seguir (Figura 19):

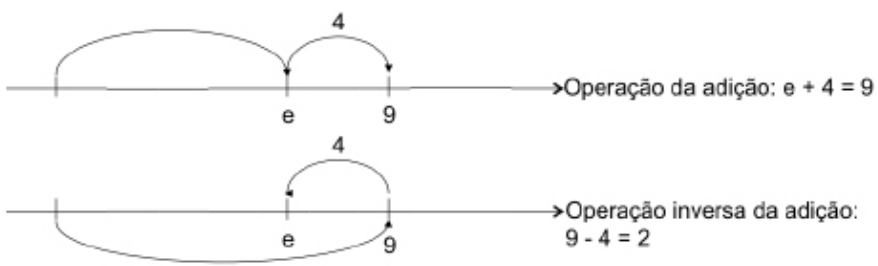

Figura 19 - Tarefa 6: Escolha da operação aritmética

Fonte: Elaboração nossa com base na proposição davydoviana

No quadro, tínhamos que $\boldsymbol{e}+\mathbf{4}=\mathbf{9}$, mas como o valor desconhecido era $\boldsymbol{e}$, o movimento operacional desenvolvido foi o inverso. Como decorrência, a partir do valor do todo (9) e de uma das partes (4), subtraímos a parte conhecida do todo: $9-4=\boldsymbol{e}(\boldsymbol{e}=5)$.

Por fim, apresentamos o exemplo referente à quarta coluna, no qual foi considerada a operação inversa da comutativa, conforme figura 20:
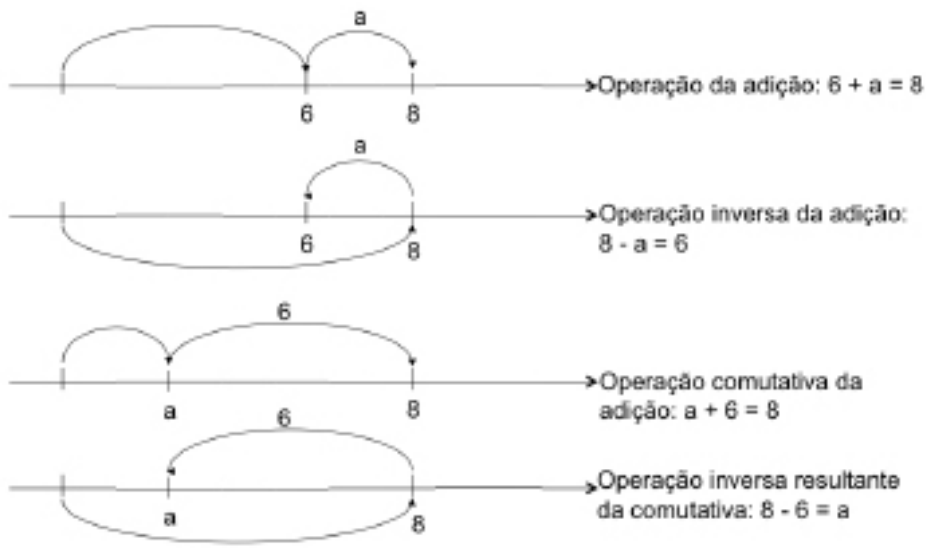

Figura 20 - Tarefa 6: Escolha da operação aritmética

Fonte: Elaboração nossa com base na proposição davydoviana 
Na quarta coluna aparece $\mathrm{k}=8, \boldsymbol{e}=6, \boldsymbol{a}=$ ?. Vale lembrar que o número $\boldsymbol{k}$ representa o valor do todo, também, o número $\boldsymbol{e}$ como uma das partes. A tarefa consiste em determinar o valor da outra parte $(\boldsymbol{a})$. O quadro apresenta a seguinte situação: $6+\boldsymbol{a}=8$ (primeiro esquema da figura 20). Como determinar o valor de $\boldsymbol{a}$ ? Seria pela operação inversa? Qual a operação a ser realizada? De acordo com Caraça (1951), conforme mencionado anteriormente, temos que a inversa de $6+$ $\boldsymbol{a}=8$ consiste em: $8-\boldsymbol{a}=6$ (segundo esquema da figura 20). Isso significa que ainda não é possível determinar o valor de $\boldsymbol{a}$. Tal possibilidade só ocorre a partir da operação inversa obtida pela comutativa, isto é, $6+\boldsymbol{a}=8$, que consiste em $\boldsymbol{a}+6=$ 8 (terceiro esquema da figura 20), cuja inversa é $8-6=\boldsymbol{a}$ (quarto esquema da figura 20). Finalmente, surge a possibilidade de determinarmos o valor de $\boldsymbol{a}$. Se $8-6=\boldsymbol{a}$, então $\boldsymbol{a}=2$. Assim sendo, os esquemas representam o movimento inverso entre as operações de adição e subtração, conforme apresentamos nas figuras 18, 19 e 20 .

\section{Considerações finais}

Vale elucidar que as tarefas davydovianas são desenvolvidas, inicialmente, por meio de ações objetais, a partir do estudo das relações entre grandezas. Durante o processo, são introduzidos os esquemas abstratos e a reta numérica. Estas representações compõem o elemento mediador, que possibilita elevar as ações objetais ao plano mental. Cada nova tarefa davydoviana está interconectada às anteriores e compõem um sistema no qual em elas revelam, progressivamente, as significações teóricas dos conceitos em seu teor científico.

Os conceitos de adição e subtração são introduzidos com base na relação todo-partes das grandezas, na interconexão entre as significações aritméticas, algébricas e geométricas. Além disso, a proposição davydoviana contempla o movimento entre as propriedades operacionais, o que nos leva pressupor a existência do teor teórico-científico.

\section{Referências}

ALEKSANDROV, A. D. Visión general de la Matemática. In: La matemática: su contenido, métodos y significado. 1 ed. $2^{\mathrm{a}}$ reimpresión. Madrid: Alianza Universidad, 1976. p. 17-91.

CARAÇA, B. J. Conceitos fundamentais da matemática. Lisboa: Livraria Sá da Costa, 1951. 
COSTA, J. M. C. Da. Tratado de arithmetica. Lisboa: Imprensa Nacional, 1866.

DAVÝDOV, V.V. Tipos de generalización en la enseñanza. $3^{\mathrm{a}}$. ed. Habana: Editorial Pueblo y Educación, 1982.

. La enseñanza escolar y el desarrollo psiquico. Investigación teórica y experimental. Trad. Marta Shuare Moscú: Editorial Progreso, 1988.

FERREIRA, Érica da Silva Moreira. Quando a atividade de ensino dá ao conceito matemático a qualidade de educar. 2005. 127 f. Dissertação (Mestrado em Educação) - Universidade Estadual de Campinas, Campinas.

LIBANEO, J. C. A didática e a aprendizagem do pensar e do aprender: a teoria histórico-cultural da atividade e a contribuição de Vasili Davydov. Rev. Bras. Educ., Rio de Janeiro,n. 27, dez. 2004. Disponível em: <http://www.scielo.br/scielo.php?script=sci_arttext\&pid=S1413-24782004000300002\&lng=pt\&nrm=iso $>$. Acesso em: 21 de junho de 2011.

ROSA, Josélia Euzébio da. Proposições de Davýdov para o ensino de matemática no primeiro ano escolar: inter-relações dos sistemas de significações numéricas. 2012. 244 f. Tese (Doutorado em Educação). Área de concentração: Educação Matemática - Universidade Federal do Paraná, Curitiba.

ДАВЫДОВ, В. В. О. et al. Математика, 1-Kjiacc. Mockba: Mnpoc - Аргус, 2012. Davidov, V.V. Matemática, $2^{\mathbf{a}}$ série. Livro didático e de exercícios para os estudantes da primeira série. Moscou: MIROS, Argus, 2012.

ГОРБОВ, С. Ф. МИКУЛИНА Г. Г.; САВЕЛЬЕВА О. В.. Обучение математике. 2 класс: Пособие для учителей начальной школы (Система Д.Б.Эльконина - В.В. Давыдова). 2-е ида. перераб. - М.:ВИТА-ПРЕССб, 2009. Ensino de Matemática. 2 ano: livro do professor do ensino fundamental (sistema do D.B.Elkonin - V.V. Davidov)/ S.F.Gorbov, G.G.Mikulina, O.V.Savieliev - 3-a edição, - Moscou, VITA-PRESS, 2009.

Submetido em fevereiro de 2013 Aprovado em setembro de 2013 